\title{
Are BRICS Countries Winning the War on HIV/AIDS? Magnitude and Risk Factors
}

\author{
Geoffrey Setswe $^{a}$, Olive Shisana ${ }^{b}$, Nompumelelo Zungua, Matshaba Mothiane ${ }^{a}$
}

\begin{abstract}
The aim of this study was to analyse the responses to HIV/AIDS in BRICS (Brazil, Russia, India, China and South Africa) countries to determine if they are winning the war on this pandemic. The authors used a comparative case study approach and multiple data sources on HIV prevalence, incidence, mortality, and risk factors of HIV. BRICS has $42 \%$ of the world's population, a total of 11.1 million people living with HIV (PLHIV) and an average HIV prevalence of 2.8\%. Overall, there were 11.1 million PLHIV, 739,909 new infections, and 592,786 deaths in BRICS countries in 2012. The magnitude of HIV in BRICS countries was Brazil (.5\%), Russia (1.1\%), India (.3\%), China (.1\%), and South Africa (12.2\%). New infections declined by $30 \%$ or more and overall prevalence and deaths also declined in Brazil, India, China, and South Africa. The epidemic has stabilized in Brazil at .6\%. Russia has one of the world's fastest-growing HIV epidemics, India has the largest burden of HIV in Asia and South Africa has the largest number of PLHIV. During a 10 year period, Russia had a 47\% increase in new HIV infections. This suggests that Russia may be losing the battle against HIV at this stage. On the other hand, India and South Africa seem to have turned the corner with declines in HIV infections of $43 \%$ and $38 \%$ respectively.
\end{abstract}

\section{Keywords}

BRICS (Brazil, Russia, India, China and South Africa), HIV/AIDS, magnitude, risk

Much has been done to reduce new infections, decrease mortality, and improve the quality of lives of people living with HIV since 1983 when the disease was discovered. UNAIDS (The Joint United Nations Programme on HIV and AIDS) (2014a) estimates that since the beginning of the HIV epidemic, about 70 million people have been infected by the virus and 35 million have died due to the virus. At the end of 2012, 35.2 million people were living with HIV globally. An estimated .8\% of adults aged 15-49 years are living with the virus. About 1.7 million people died of AIDS-related illnesses worldwide in 2011. Sub-Saharan Africa accounts for $69 \%$ of people living with HIV worldwide (Haregu et al. 2013) and approximately one in 20 (4.9\%) are living with the virus.

BRICS (Brazil, Russia, India, China and South
Africa) countries represent $42 \%$ of the world's population, around $25 \%$ of the world's gross national income and about $40 \%$ of the global burden of disease (Acharya et al. 2014). These five countries are all emerging economies that have all struggled with the onset and spread of HIV in recent years (Kulik 2013).

Largely influenced by the global level responses, national level responses to HIV/AIDS apply a

\footnotetext{
aBrics Research Centre (Human Sciences Research Council), South Africa

bEvidence Based Solutions, South Africa

Correspondent Author:

Geoffrey Setswe, BRICS Research Centre, Human Sciences Research Council, HSRC Building, 134 Pretorius Street, Pretoria 0002, South Africa

E-mail: gsetswe@hsrc.ac.za
} 
multi-sectoral approach and broad governmental efforts in order to mitigate the multi-faceted risk factors and impacts of the epidemic (UNAIDS 2013). The implementation of such approaches needs well-coordinated policies/strategies and systems. A much broader literature has explored individual BRICS countries' responses to specific health issues, such as HIV/AIDS (Decoteau 2013; Wu et al. 2007; Wallander 2005; Parker 2009). However, this study and two other studies (Lieberman 2009; Gomez 2013) have taken a country comparative approach toward examining the BRICS' response to this epidemic.

As the UNAIDS Executive Director talked about "beginning of the end of AIDS" (UNAIDS 2014b), the authors analysed the responses to HIV/AIDS in BRICS countries to determine if they are winning the war on this pandemic. This paper explores variation in the response to HIV/AIDS in BRICS countries, focusing on the burden of disease and risk factors or modes of transmission and suggesting needed areas of improvement.

\section{METHODS}

\section{Scope of the Study}

The major construct of this study was the national or strategic level response to HIV/AIDS. Adapted from the WHO (World Health Organization)'s health system framework, the overarching themes that were analysed in this study were the magnitude and risk factors of HIV/AIDS in the five countries (WHO 2011) uncovering contextual factors.

\section{Study Design}

This investigation used a comparative case study approach as the main focus was on how the five BRICS countries were responding to the HIV/AIDS epidemic.

\section{Selection of Cases and Study Setting}

BRICS is a select group of five large, emerging economies that are distinguished from a host of other promising emerging markets by their demographic and economic potential to rank among the world's largest and most influential economies in the twenty-first century. Population sizes in the selected countries in 2012 were 199 million in Brazil, 143 million in Russia, 1.24 billion in India, 1.39 billion in China, and 52.3 million in South Africa (WHO 2014). The five countries were self-selected by virtue of being members of BRICS.

\section{Data Collection}

Multiple data sources were used in this study. These included performance reports, databases, survey reports, and peer-reviewed literature. The primary documents reviewed were the most recent health, HIV/AIDS reports and publications which were available in the public domain. Most recent annual health sectors and HIV/AIDS were among the reports reviewed $^{1}$. Information from global and national level survey reports and other peer-reviewed literature relevant to health systems' response to HIV/AIDS with special reference to the case countries was also used.

This study also drew on publicly available AIDS-related data collected in 2013/4 from the Ministries of Health of countries as part of the South Africa BRICS Think Tank incubated by the Human Sciences Research Council (HSRC). The data contain variables related to the capacity of countries to respond to HIV/AIDS in four areas: (1) HIV prevalence; (2) HIV incidence; (3) mortality; and (4) risk factors or mode of transmission of HIV.

\section{Data Collection Tools}

Using the four overarching themes, a data abstraction template was developed. Theme-based matrices were independently populated for each of the countries on HIV/AIDS. All the HIV/AIDS data from the Global Health Observatory and other sources collected from the five case countries were extracted and included in 
this study (Lieberman 2009).

The sub-themes of the study are: (1) HIV prevalence; (2) HIV incidence; (3) mortality from AIDS-related factors; and (4) modes of transmission of HIV. The sub-themes were used as categories in the coding process.

Trends in HIV prevalence among persons aged 15-24 years were used as a proxy indicator for the new infections in the population.

\section{Data Analysis}

The overall approach was content analysis. Comparative analysis of strategic parallels within a country (within case) was used. In this process, items to be compared were the core components of the response. The focus of analysis included identifying items for comparison, characteristics to be compared, degrees of similarity, and strategic importance of similarities. The findings were summarized using integrative synthesis (Sandelowski et al. 2012).

\section{FINDINGS}

The findings are presented for each of the five countries.

\section{Magnitude and Risk Factors for HIV/AIDS in Brazil}

HIV prevalence. The number of Brazilians living with HIV was estimated at 490,000 with an HIV prevalence of .5\% in 2012 (Avert 2013a). HIV prevalence in the population aged 15 to 49 has been stable at .6\% since 2004 with .4\% in females and .8\% in males. Prevalence of HIV in the population in 2012 was $.4 \%$ in the general population, $.5 \%$ in men, $.3 \%$ in women, $10.5 \%$ in men who have sex with men (MSM), $4.9 \%$ in sex workers, and $5.9 \%$ in drug users.

There were 656,701 cumulative AIDS cases between 1980 and 2012, of which 397,662 (65.4\%) were male and 210,538 (34.6\%) were female. The epidemic is now concentrated in certain vulnerable population sub-groups such as MSM, female sex workers (FSW), and injecting drug users (IDUs).

Incidence of HIV. Figure 1 shows a trend in AIDS incidence in Brazil by sex and year of diagnosis from 1998 to 2010. On average, 36,000 new cases occur per year. The AIDS incidence rate has stabilized at 19/100,000 inhabitants.

Mortality. Figure 2 shows a stable trend in AIDS mortality rates from 1998 to 2010. The number of deaths per year was approximately 11,500. In absolute numbers, an expressive reduction in AIDS cases can be seen in children aged under five, having fallen from 846 cases in the year 2001 to 745 in 2011. When comparing the year 2000 with the year 2010, there was a $55 \%$ reduction in mortality rates. This result confirms the efficacy of the policy on the reduction of vertical HIV transmission (mother-to-child) (Department of STD, AIDS and Viral Hepatitis 2012).

Modes of transmission. Men still account for the majority of infections in Brazil, women represent an increasing share of the epidemic with the ratio of male-to-female AIDS cases shrinking from 15-to-1 in 1986 to 1.7-to-1 in 2011 (Avert 2013a).

In Brazil, the share of IDU as the mode of transmission in new AIDS cases declined from 27.5\% to $5 \%$ among adult males, and $21.9 \%$ to $2 \%$ among adult females between 1995 and 2011. HIV prevalence among IDUs was estimated to be around 5.9\% at the end of 2009 (Avert 2013a).

Sexual transmission is the primary mode of infection among people aged over 13. Eighty-three point one percent (83.1\%) of female cases resulted from heterosexual intercourse with people infected with HIV, compared with $43.5 \%$ of male cases resulting from heterosexual transmission, $24.5 \%$ from homosexual transmission and $7.7 \%$ from bisexual relations. The remainder occurred through blood and mother-to-child transmission.

The epidemic in Brazil is concentrated because HIV prevalence is below $1 \%$ in the general population 


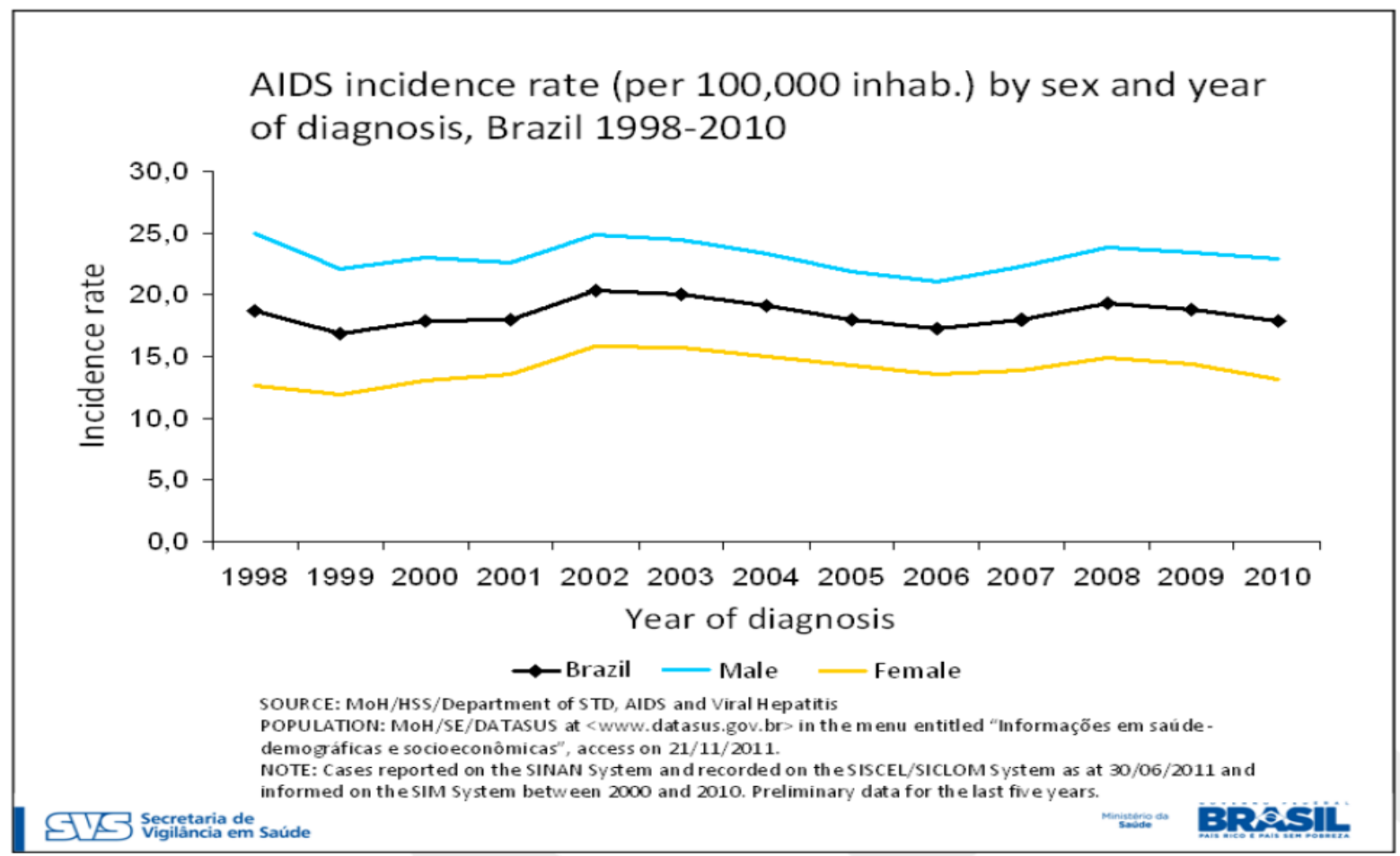

Figure 1. Trend in AIDS Incidence in Brazil by Sex and Year of Diagnosis (1998-2010). Source: Department of STD, AIDS and Viral Hepatitis (2012).

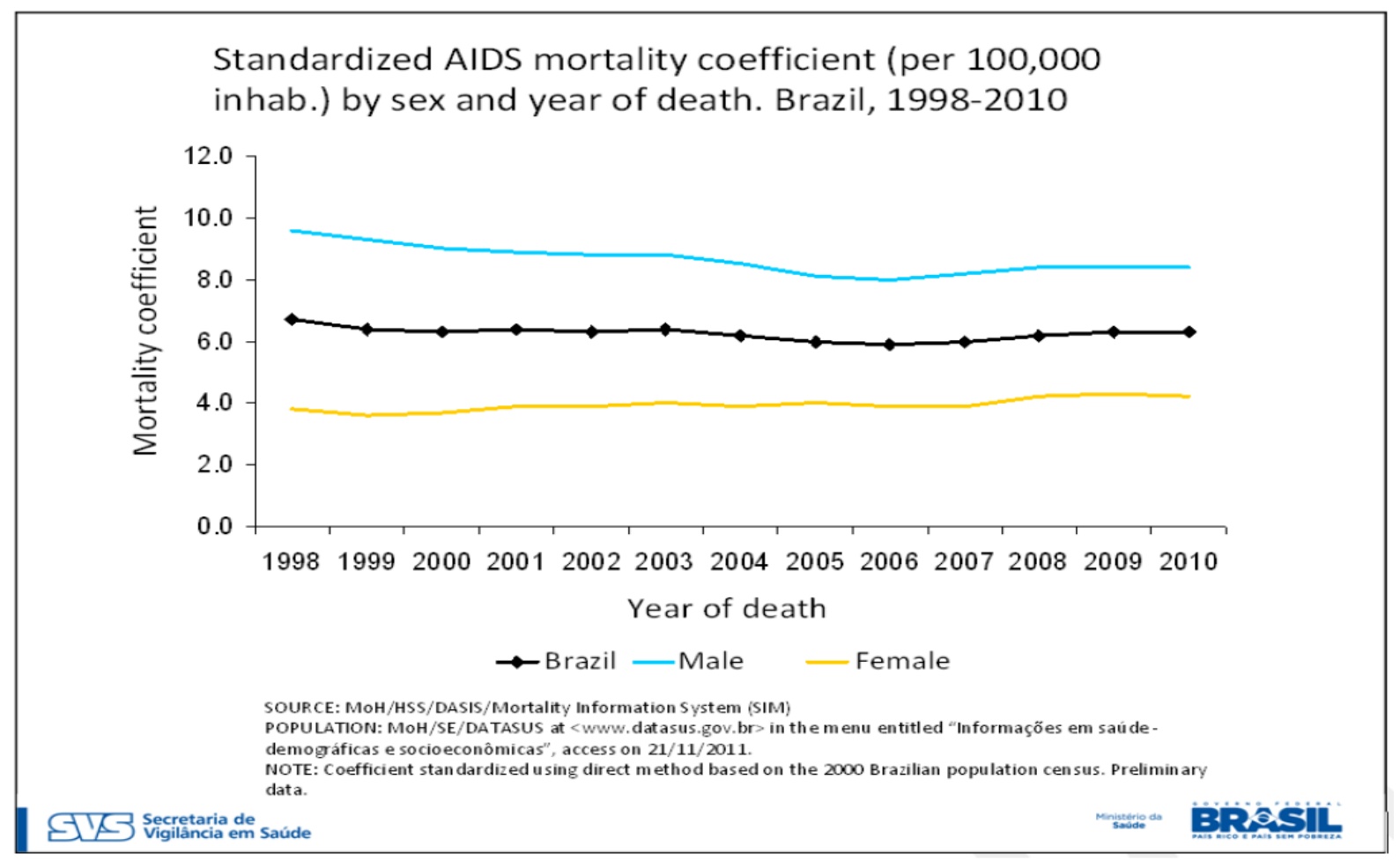

Figure 2. Trend in the Mortality From AIDS in Brazil by Sex (1998-2010). Source: Department of STD, AIDS and Viral Hepatitis (2012). 
but exceeds $5 \%$ in specific at-risk populations like IDUs and sex workers. Over the last 12 years, the percentage of HIV cases has fallen in the general population aged 15 to 24 , even though there has been an increase of $10.1 \%$ in men who have sex with other men in the same age group. In 2010, for every 16 MSM in this age group living with AIDS there were 10 heterosexuals. In 1998, this ratio was 12 to 10 (Department of STD, AIDS and Viral Hepatitis 2012).

\section{Magnitude and Risk Factors for HIV/AIDS in the Russia Federation}

HIV prevalence. The Russian Federation reports it had 617,018 people living with HIV (PLHIV) in 2012. However, UNAIDS and WHO estimate between 730,000 and 1.3 million PLHIV in Russia at the end of 2011. Around 720,000 people have been diagnosed with HIV in Russia since 1987, when the first case was officially registered (Russia Beyond the Headlines 2012; Onishchenko 2013).

Russia accounts for the majority (nearly 70\%) of HIV cases in Eastern Europe and Central Asia and has one of the fastest growing HIV epidemics in the world with a national HIV/AIDS prevalence estimated to be 1.1\% (Morrison and Kates 2006). Figure 3 shows an increasing trend in HIV prevalence in Russia from 2001 to 2009.

Incidence of HIV. In 2011, 67,317 people were newly diagnosed with HIV. This was 44.1 HIV cases per 100,000 population; the highest reported rate in the WHO European Region and one of the world's fastest-growing HIV epidemics. New infections increased by 13\% in 2011 to 70,453 in 2012 and increased a further 10\% in 2013.

Russia registered more than 69,000 new cases of HIV in 2012 running counter to the global trend. The proportion of new incidences was $41 \%$ female as compared with 59\% male. HIV morbidity is concentrated in the age-group 20-29 indicating that the age of onset is increasing (WHO 2013).
Mortality. Figure 4 shows HIV disease mortality trend in Russia from 1990 to 2009. The HIV/AIDS mortality rate is growing. Between 38,000 and 78,000 people are estimated to have died of AIDS-related causes during 2011, 125,557 by 2012. The mortality rate grew by 14\% year-on-year in 2012 (Russia Beyond the Headlines 2012; Onishchenko 2013). Figure 5 shows the share of HIV prevalence and AIDS deaths among IDUs in Russia between 2007 and 2009.

Modes of transmission. For more than 10 years, the main cause of HIV transmission has been the use of non-sterile syringes for the intravenous injection of drugs. As of the end of 2012, more than half (57.6\%) of all new infections were caused by intravenous injections. The estimated number of illegal drug users in Russia was five million in 2013. Illegal opiates were used by an estimated 1.6 million people. An average $37.2 \%$ of intravenous drug users live with $\mathrm{HIV}$ and, in some regions, the figure is as high as $75 \%$. The majority of HIV infections officially reported in Russia have been among IDUs due to the large rises in the prevalence of illicit drug use, including opiate injection, among teenagers and young adult Russians (Amirkhanian, Tiunov, and Kelly 2001).

The main sources of HIV infection are injecting drug use of narcotics with non-sterile syringes at $56.2 \%$ and homosexual relationships at $41.4 \%$. The database of the Federal Statistics Agency of the Russian Federation and UN (United Nations) Office on Drugs and Crime reported that $64 \%$ of PLHIV in 2012 were male (UN Office on Drugs and Crime [UNODC] 2012).

Sexual contact, mostly heterosexual, is gaining in prominence. Almost $40 \%$ of the people that contracted HIV in 2011 did so through sexual contact-a 4.5\% increase on the previous three years (Kozlov 2011).

A study of unmarried young people in vocational training schools in Russia found that $71 \%$ were sexually experienced and that most had first intercourse before 


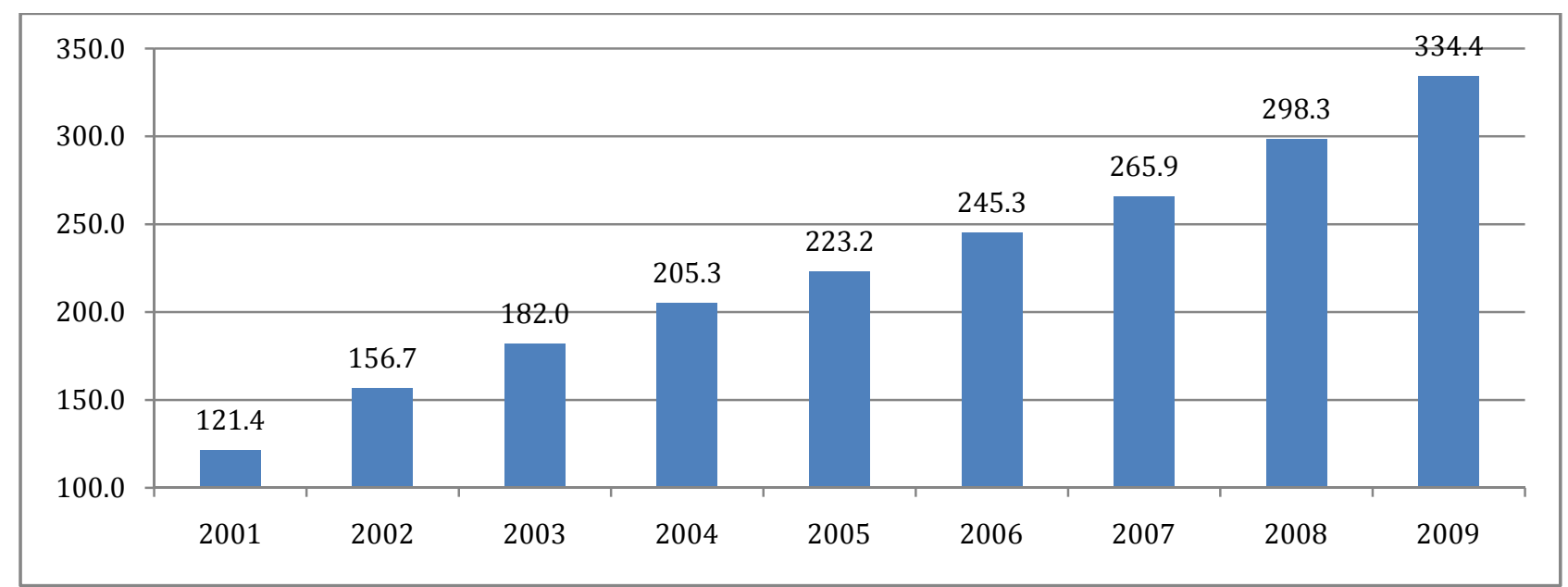

Figure 3. HIV Prevalence Trend per 100,000 in Russia (2001-2009). Source: Kozlov (2011).

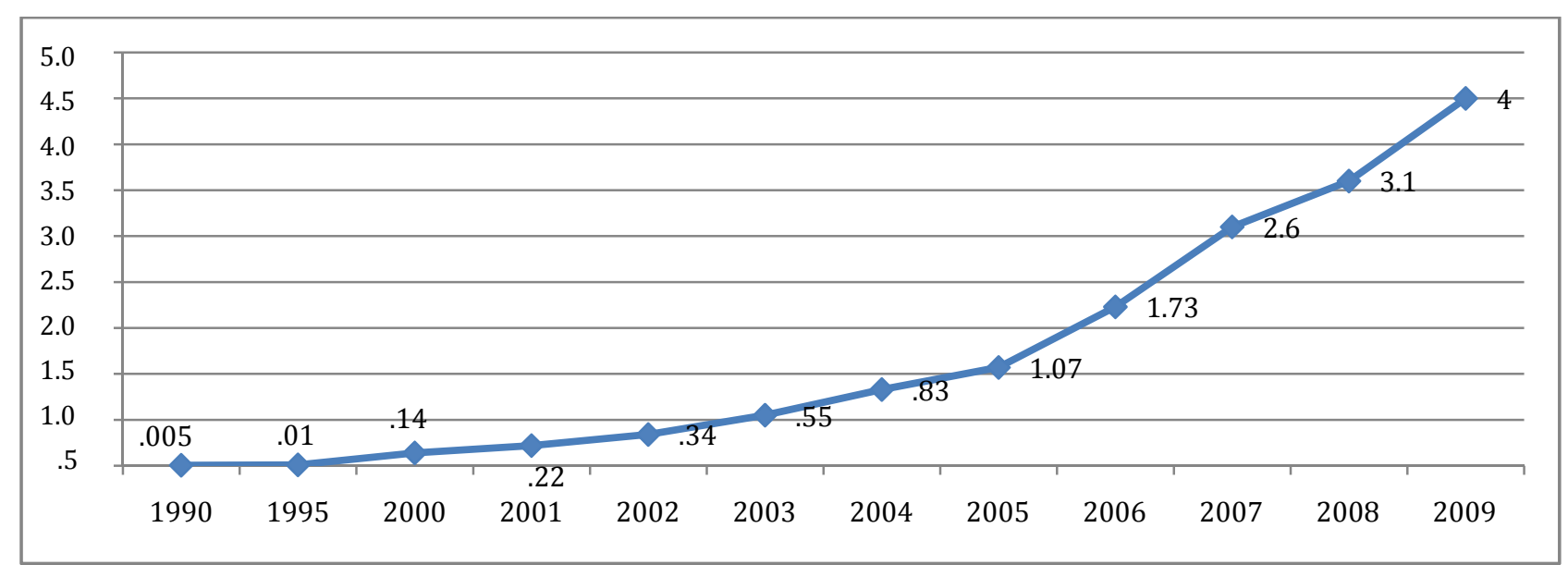

Figure 4. HIV Disease Mortality Trend, per 100,000 in Russia (1990-2009). Source: Kozlov (2011).

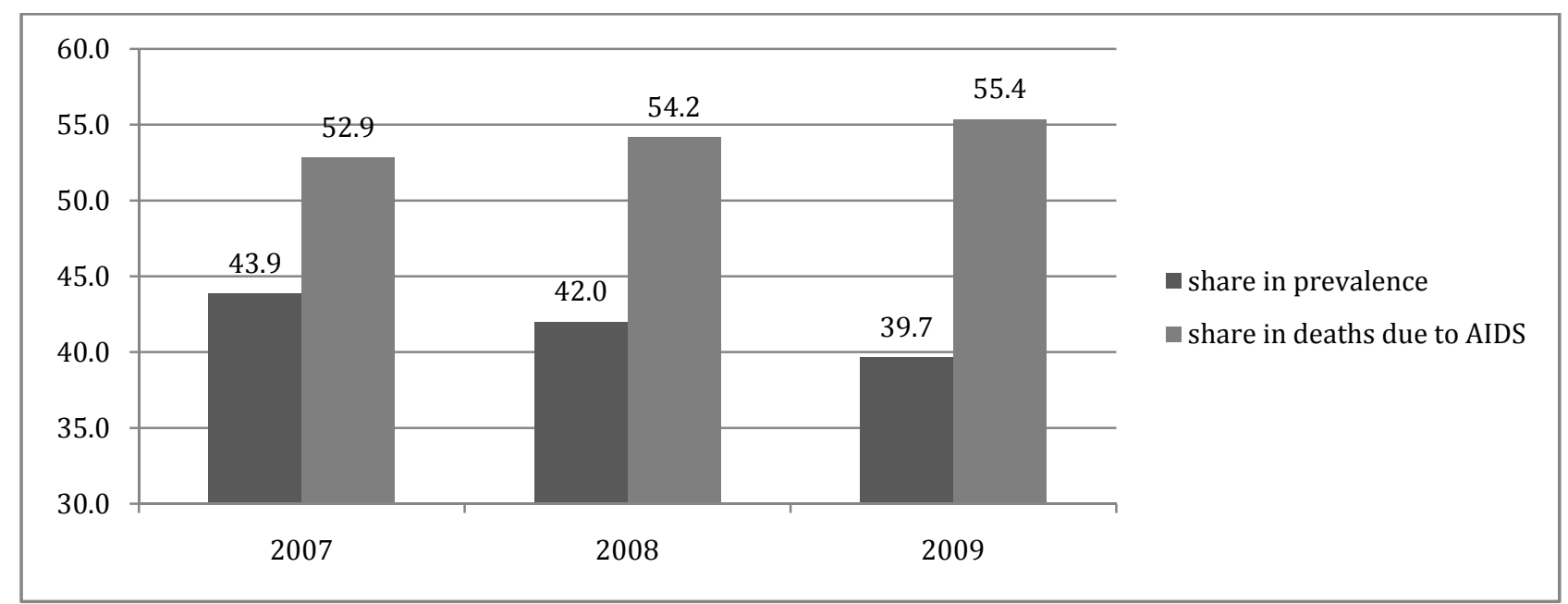

Figure 5. HIV Prevalence and AIDS Mortality Among IDUs in Russia (2007-2009). Source: Kozlov (2011). 
the age of 15. Fifty-one percent (51\%) had multiple sexual partners in the past year. Only $12 \%$ of sexually experienced young people said that they consistently used condoms, while $74 \%$ rarely or never used them. Misconceptions about AIDS are prevalent among university students. A survey conducted in 1999 found that $70 \%$ of Russian college students believed that they do not face any serious risk of contracting HIV during casual sexual encounters (Amirkhanian et al. 2001).

\section{Magnitude and Risk Factors for HIV/AIDS in India}

HIV prevalence. With 2.4 million PLHIV and HIV prevalence of $.27 \%$, India carries the largest burden of HIV infections in Asia and the third largest in the world in 2012 after South Africa and Nigeria. HIV prevalence appears to be low in the general population (.27\% in 2012) but disproportionately high among high-risk groups. The epidemic is concentrated among vulnerable populations at high risk of HIV, such as IDUs, FSW, MSM, and sexually transmitted disease (STD) clinic attendees (Government of India 2012).

HIV prevalence among women attending antenatal clinics in India was $.40 \%$ in 2012. Much higher percentages are found among people attending STD clinics (3.6\%), FSW (2.67\%), IDUs (7.14\%), and MSM (4.43\%). Prevalence is higher in urban areas (.35\%) than in rural areas (.25\%) (Avert 2013b).

Incidence of HIV. It is estimated that around 116,456 new HIV infections among adults and around 14,500 new infections among children occurred during 2011. People living with HIV estimated new infections in 2011 among adults, the six high prevalence states account for $31 \%$ of new infections. The estimated number of new annual HIV infections has declined by 56\% over the past decade (2000-2009). But, some low prevalence states have shown a slight increase in the number of new infections over the past two years (National AIDS Coordinating Organisation
[NACO] 2012). India had an overall reduction of 57\% in the annual new HIV infections among the adult population (NACO 2012).

Mortality. In 2009, 172,000 people were reported to have died from AIDS-related causes. Wider access to ART (antiretroviral treatment) has resulted in a $29 \%$ reduction in estimated annual deaths due to AIDS-related causes between 2007 and 2011. In 2009, 172,000 people were reported to have died from AIDS-related causes (Avert 2013b).

Modes of transmission. Figure 7 shows the HIV prevalence among key populations in India from 2008 to 2009. The Indian epidemic is concentrated among vulnerable populations at high risk for HIV, but it is also becoming generalised. The concentrated epidemics are driven by unprotected sex between sex workers and their clients and by injecting drug use with contaminated injecting equipment. Several of the most at risk groups have high and still rising HIV prevalence rates. According to India's National AIDS Control Organization (NACO) (2012), the bulk of HIV infections in India occur during unprotected heterosexual intercourse. Consequently, and as the epidemic has matured, women account for a growing proportion of people living with HIV, especially in rural areas. The low rate of multiple partner concurrent sexual relationships among the wider community seems to have, so far, protected the larger population. However, despite the overall prevalence remains low, even relatively minor increases in HIV infection rates in a country of more than one billion people translate into large numbers of people becoming infected.

\section{Magnitude and Risk Factors for HIV/AIDS in the People's Republic of China}

HIV prevalence. The Ministry of Health of the People's Republic of China (2012) estimated that approximately 780,000 persons were living with HIV/AIDS in China with an adult prevalence rate 


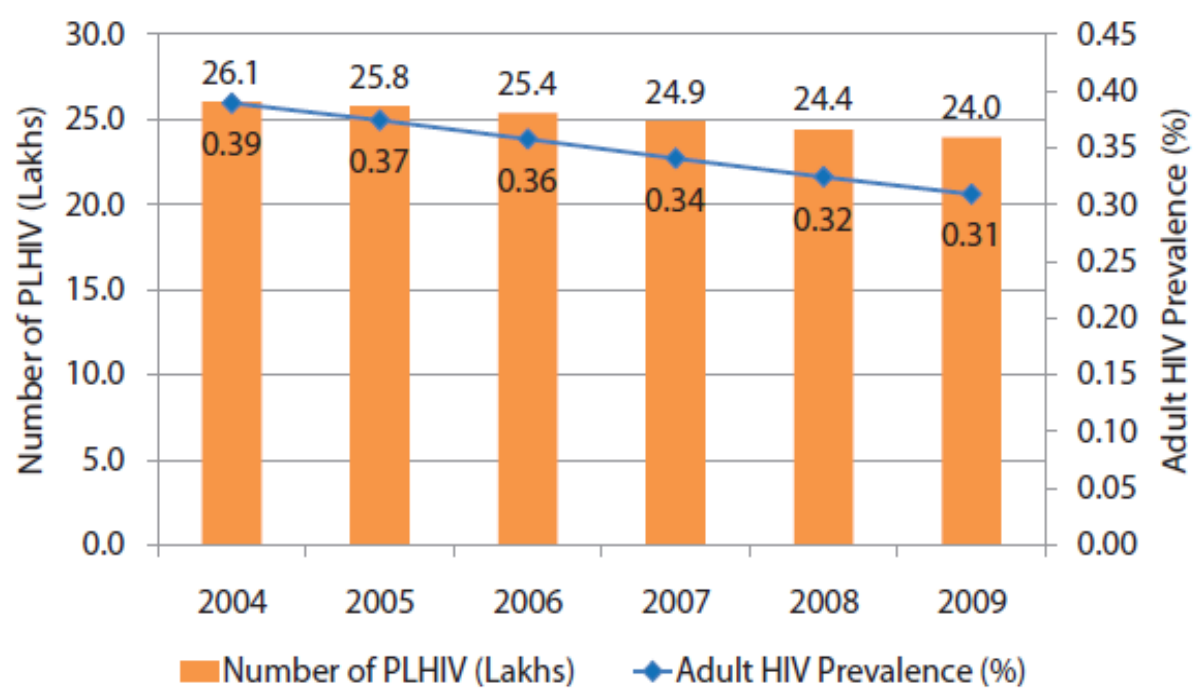

Source: Technical Report on HIV Estimations 2010

Figure 6. Trend in Adult HIV Prevalence and Number of PLHIV in India (2004-2009). Source: NACO (2012).

\section{HIV Prevalence: India, 2008-09}

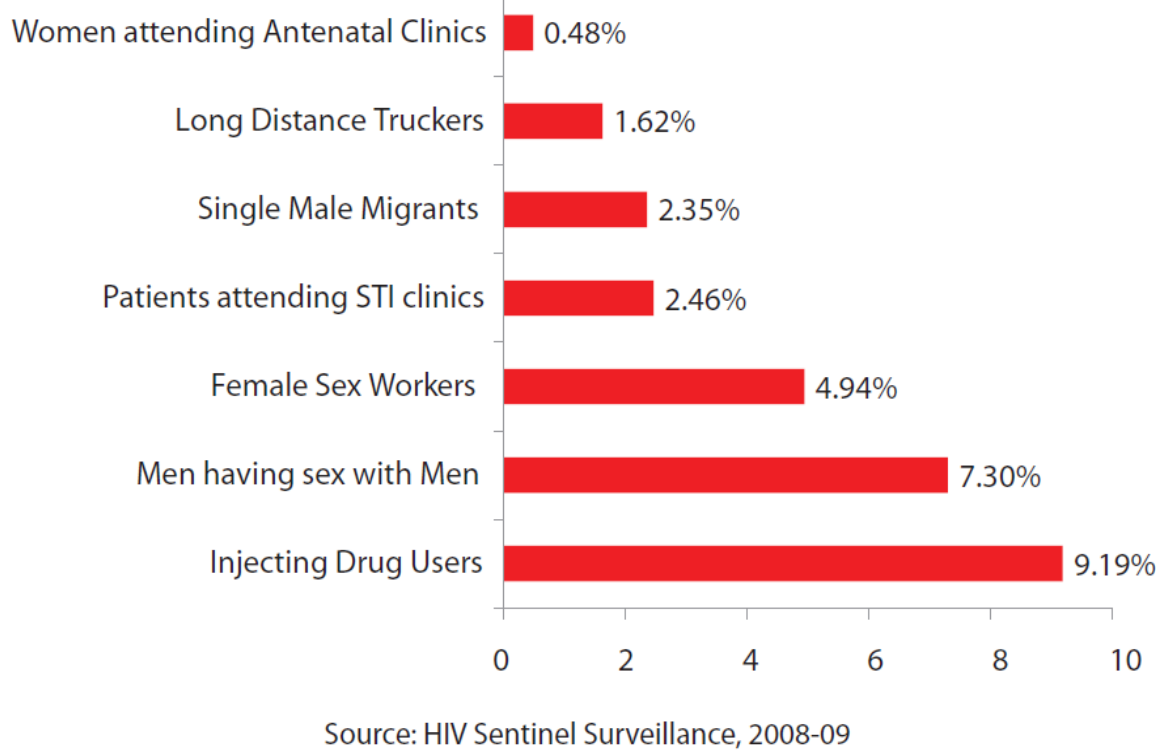

Figure 7. HIV Prevalence Among Key Populations in India (2008-2009).

of .1\%. This accounted for $.057 \%$ of the Chinese population in 2011 (United Nations General Assembly Special Session [UNGASS] 2010).

The latest national report indicated that the proportion of newly diagnosed HIV cases due to male homosexual contact has increased from $12.2 \%$ in 2007 to $32.5 \%$ in 2009 (UNGASS 2010); while the national HIV prevalence among MSM had a 4.5-fold increase in the past 10 years (i.e., from $1.4 \%$ in 2001 to $6.3 \%$ in 2011) (UNGASS 2013). The level of HIV 
prevalence in MSM is still relatively low compared with other Asian countries such as Indonesia (9.0\%) and Thailand (24.6\%) (UNGASS 2013). Figure 6 shows a trend in adult HIV prevalence and the number of PLHIV in India between 2004 and 2009.

Figure 8a shows that most of the nearly one million people living with HIV in China, live within six of China's 33 provinces: Yunnan, Guangxi, Henan, Sichuan, Xingiang, and Guangdong. These provinces report the highest number of HIV and AIDS cases, representing around $70 \%-80 \%$ of the national total (Ministry of Health of the People's Republic of China 2012).

Incidence of HIV. Figure 8b shows HIV incidence per 100 person years in various provinces in China between 2004 and 2012.

Mortality. In 2009, China reported that AIDS had become the country's leading cause of death among infectious diseases for the first time ever, surpassing both tuberculosis and rabies. During 2011, around 28,000 people died from AIDS (UNGASS 2013).

Modes of transmission. Sexual transmission is the primary mode of transmission where heterosexual transmission increased from $33.1 \%$ in 2006 to $76.3 \%$ in 2011 and homosexual transmission increased from 2.5\% in 2006 to $13.7 \%$ in 2011.

In 2012, HIV transmission among all PLHIV was $28.6 \%$ in women. In total, $46.5 \%$ of all HIV infections occurred through the heterosexual transmission route, $17.4 \%$ through homosexual transmission, $28.4 \%$ through IDU, $6.6 \%$ in former blood donors or transfusion recipients, and $1.1 \%$ in children infected through mother to child transmission (MTCT). The numbers of people who used drugs and tested positive for HIV showed a falling trend after 2005 (Ministry of Health of the People's Republic of China 2012).

HIV epidemic was initiated and mainly transmitted by sharing injecting equipment among drug users (IDUs) in China in the past decade (UNGASS 2013). Traditionally, HIV transmission has been particularly high among IDUs, MSM, and former plasma donors. However, in recent years, HIV has bridged to the general population, and now heterosexual sex has become the dominant transmission route. Nearly half of all people living ith HIV at the end of 2011 were infected through heterosexual transmission, whilst injecting drug use and sex between men accounted for just over one in four and nearly one in five infections, respectively. Other transmission routes included former blood donors or transfusion recipients (6.6\%) and MTCT (1.1\%) (Ministry of Health of the People's Republic of China 2012).

Figure 9 shows changes and trends of HIV positive testing rates from China's HIV sentinel surveillance system from 2000 to 2011. It shows how inconsistent the epidemic has grown over the years and in selected high risk groups.

\section{Magnitude and Risk Factors for HIV/AIDS in South Africa}

HIV prevalence. With .7\% of the world's population, South Africa accounts for $17 \%$ of the global burden of HIV with 6.1 million PLHIV. The epidemic in South Africa is generalized, i.e., $12.2 \%$ of the population, but also has pockets of concentrated epidemics. In 2012, South Africa had the largest number of people living with HIV/AIDS at 6.4 million with a prevalence of $12.2 \%$ (Shisana et al. 2014). The evidence from population-based HIV prevalence surveys in South Africa indicates that infection rates in this age group have been consistently declining in the country, from $10.3 \%$ in 2005 to $7.3 \%$ in 2012. Between 2002 and 2008 , only $.6 \%$ reduction in the prevalence was observed. However, between 2008 and 2012, a 1.4\% reduction has been noted, therefore showing more than double the impact observed between 2002 and 2008. This may be attributable to the effect of a number of interventions targeted to halt transmission of HIV, such as the HCT (HIV Counselling and Testing), the medical male circumcision campaigns, as well as an increased 


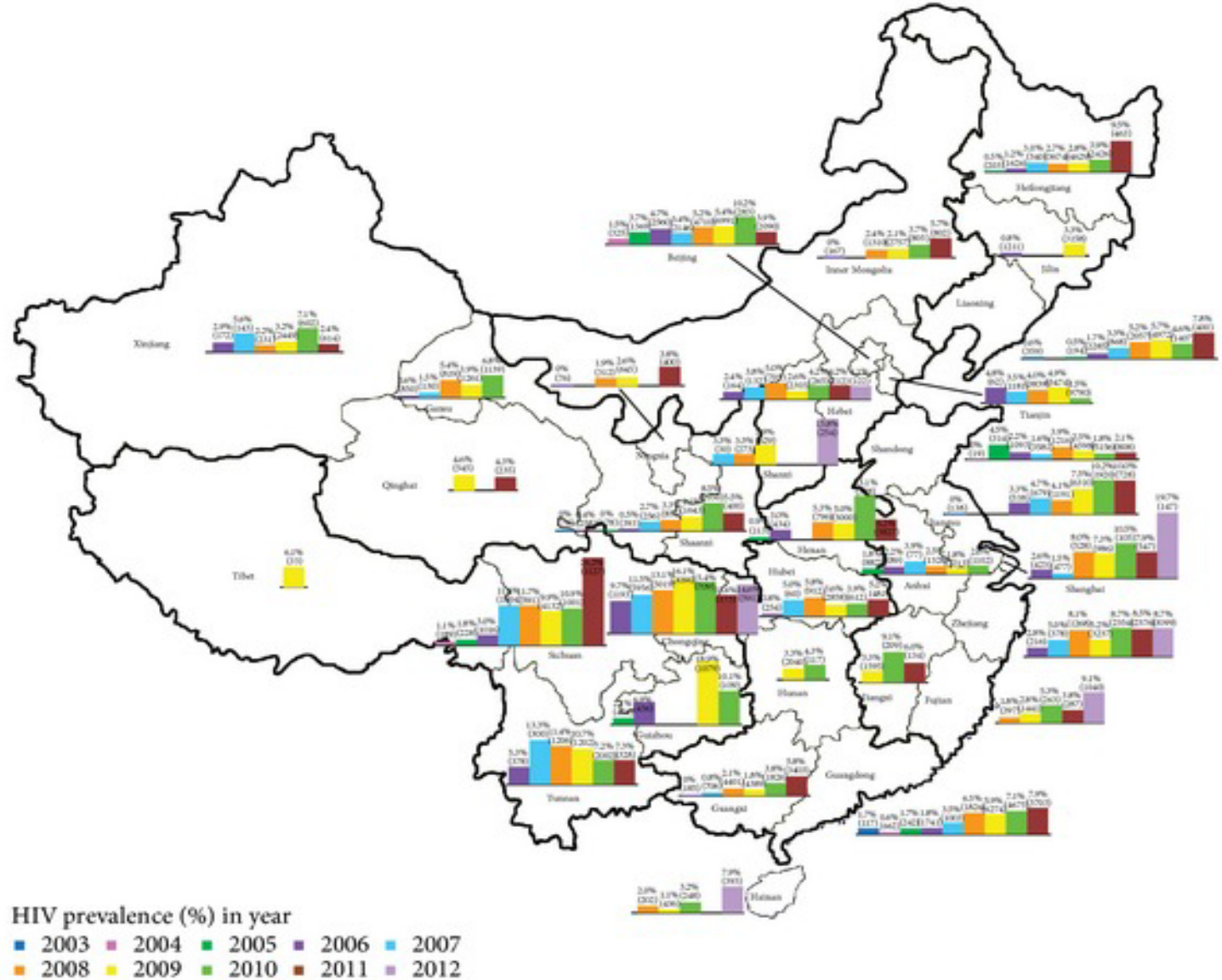

Figure 8a. HIV Prevalence (\%) in China (2003-2012). Source: Ministry of Health of the People's Republic of China (2012).
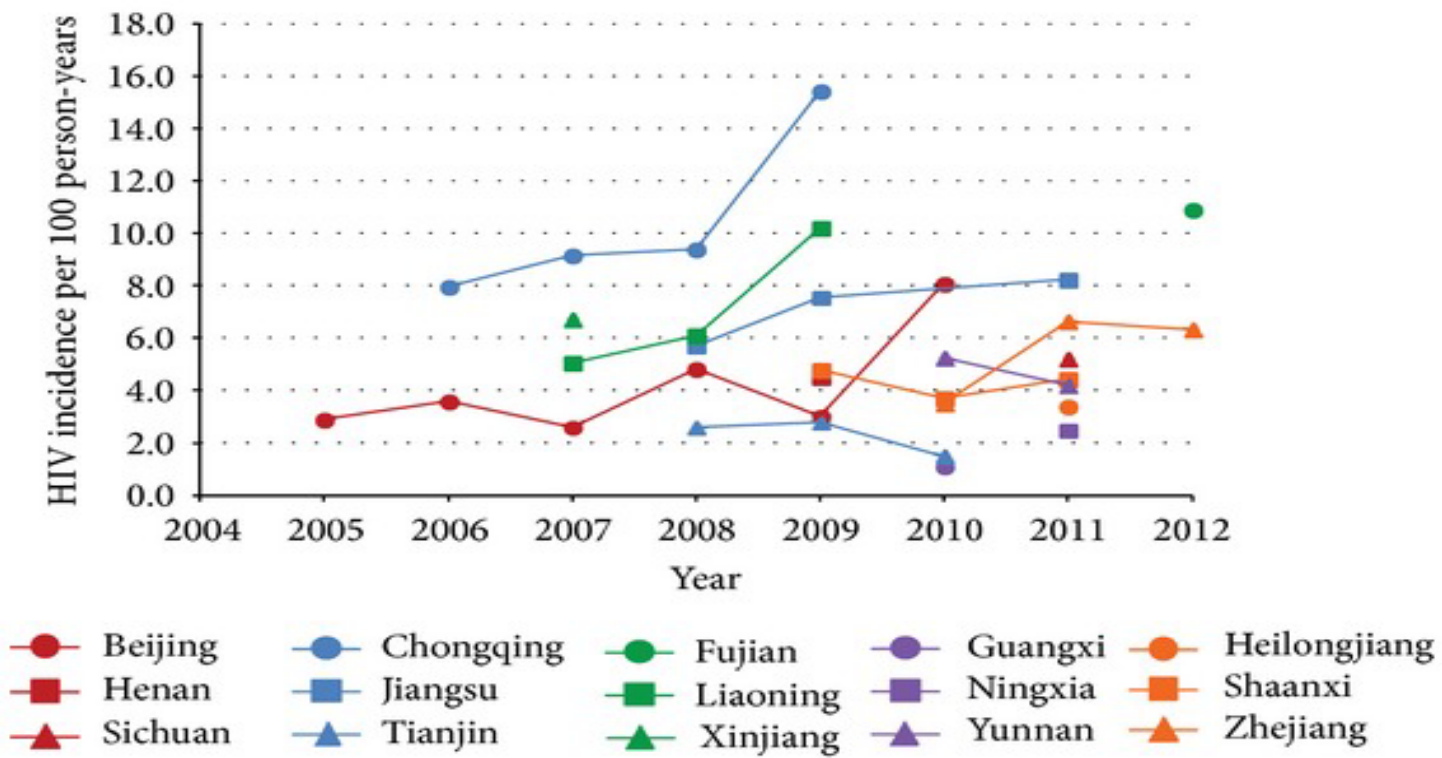

Figure 8b. HIV Incidence per 100 Person Years in China (2004-2012). Source: Ministry of Health of the People's Republic of China (2012). 


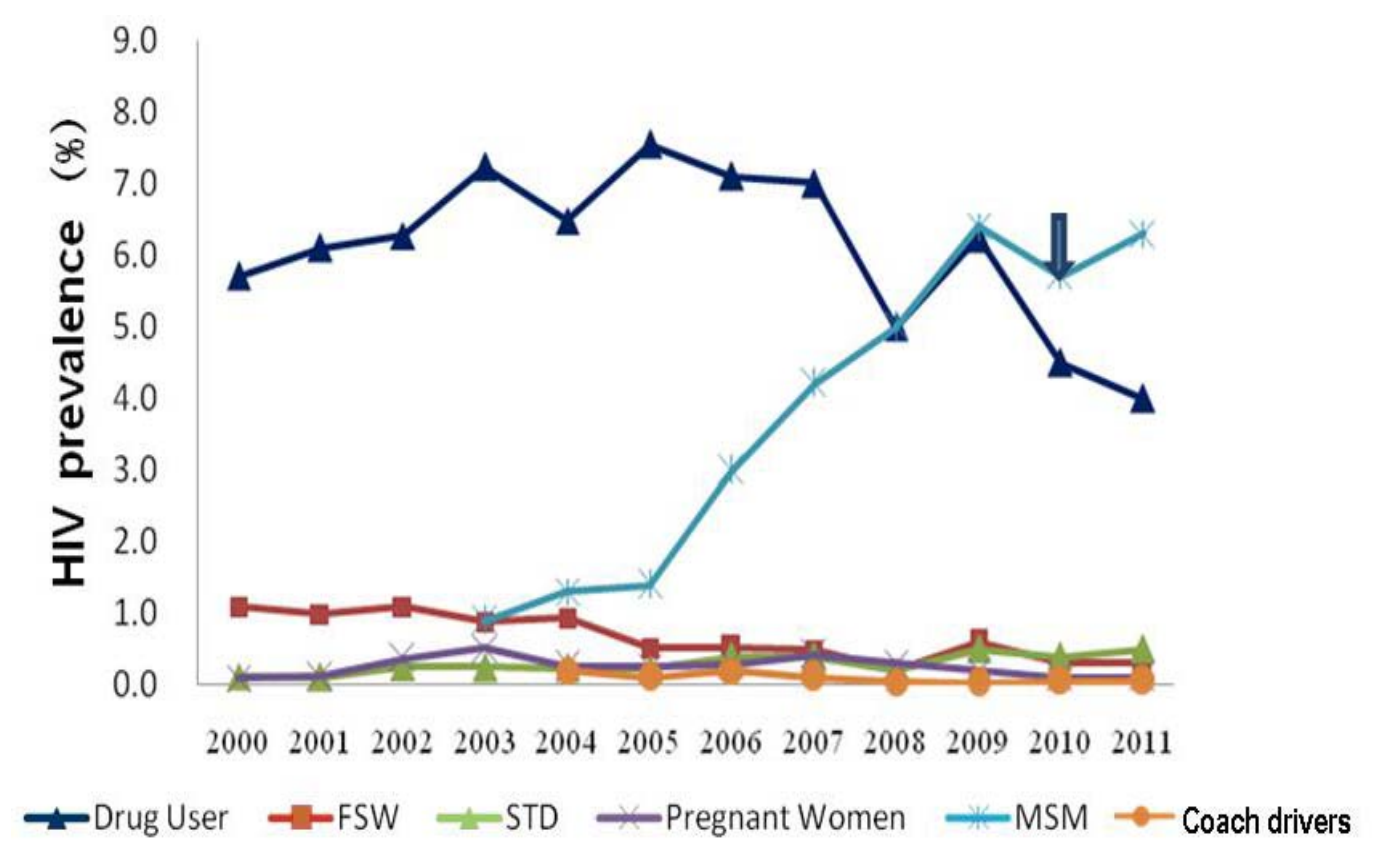

Figure 9. Changes and Trends of HIV Positive Testing Rates, China's HIV Sentinel Surveillance System (2000-2011). Source: Ministry of Health of the People's Republic of China (2012).

number of people receiving ARVs (antiretrovirals) (UNAIDS 2013b).

Figure 10 shows a trend in HIV prevalence among population aged 15-24 years, South Africa from 2002 to 2012. There was a slight increase in prevalence from 2002 to 2005, but it has been a downward trend from 2005 to 2012.

Incidence of HIV. New HIV infections dropped in youth with a decline in incidence among females aged $15-24$ years, from $5.3 \%$ in $2002-2005$ to $2.1 \%$ in 2008-2012 (Shisana et al. 2014).

Mortality. In 2010, the number of deaths processed by Statistics South Africa (2013) was 543,856 , a $6.2 \%$ decline from the year before with the highest number of deaths among those aged 35-39 and 30-34. Overall, there were slightly more male than female deaths.

Modes of transmission. HIV prevalence among MSM in South Africa is an estimated 9.9\% with roughly $9.2 \%$ of all new HIV infections in the country related to this key population. HIV prevalence among sex workers varies between 34\% and 69\% depending on the geographical area. In 2010, sex work accounted for an estimated $19.8 \%$ of all new HIV infections in South Africa (South African National AIDS Council [SANAC] 2012) and an estimated $60 \%$ of sex workers are HIV positive (SANAC 2012).

\section{Discussion: Magnitude of HIV/AIDS in All BRICS Countries}

With $42 \%$ of the world's population, BRICS countries have an estimated 11.1 million people living with HIV/AIDS with an average prevalence of $2.8 \%$. This is almost one-third of the 35.3 million people living with HIV/AIDS globally. South Africa and India have contributed significantly to the number while South Africa's high prevalence has also contributed to the high prevalence ratio.

Figure 12 summarises HIV incidence and AIDS-related deaths in BRICS countries in 2012. Overall, there were 739,909 new infections and 592,786 deaths with a residual of 147,123 in BRICS countries in 2012. South Africa still contributes the largest number new infections $(469,000)$ and also the 


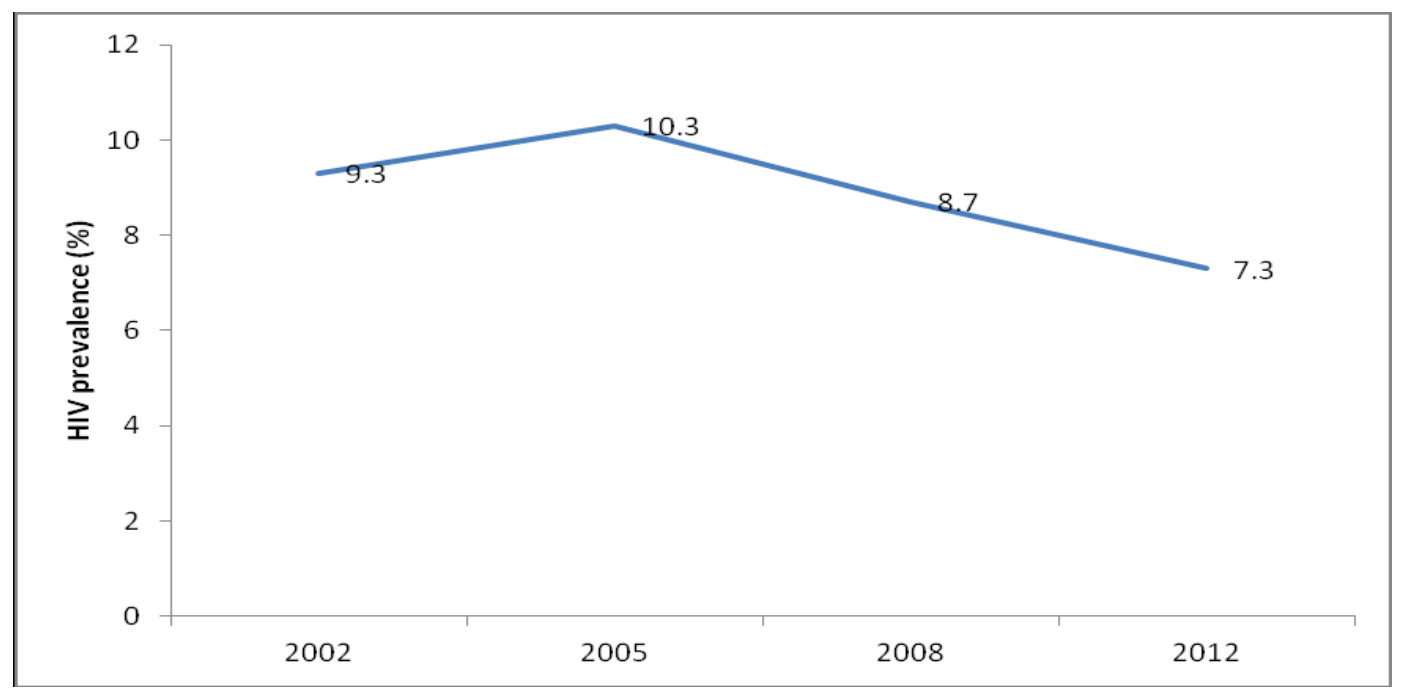

Figure 10. Trend in HIV Prevalence Among Population Aged 15-24 Years, South Africa (2002-2012). Source: Shisana et al. (2014).

largest number of AIDS-related deaths $(280,000)$, although there is a significant contribution from India $(147,729)$ and the Russian Federation $(125,557)$.

BRICS countries are not winning the war against AIDS as yet, as the incidence and AIDS-related deaths have not dropped to significantly low levels.

Figure 13 shows change in new HIV cases in Russia, India, and South Africa over a 10 year period. During this period, Russia had a $47 \%$ increase in new HIV cases. This is significant and begs the question: Is Russia losing the battle against AIDS?

However, India and South Africa seem to have turned the corner with declines in HIV incidence of $43 \%$ and $38 \%$ respectively.

Table 1 shows changes in new HIV infections, deaths, and prevalence between 2001 and 2012 for BRICS countries. New infections declined by $30 \%$ or more and overall prevalence and deaths also declined in Brazil, India, China, and South Africa. The epidemic has stabilized in Brazil at .6\% and MTCT of HIV has almost been eliminated.

New infections and PLHIV increased by $30 \%$ or more in Russia and has one of the world's fastest-growing HIV epidemics. India has the largest burden of HIV in Asia and third largest in the world while South Africa has $17 \%$ of the global burden of HIV with the largest number of PLHIV. HIV prevalence has been stable in India and China in the past five years. Prevalence of HIV remains low (.058\%) in China even though the epidemic is becoming severe in some areas.

The magnitude of HIV/AIDS in BRICS countries was Brazil (.5\%), Russia (1.1\%), India (.3\%), China (.1\%), and South Africa (12.2\% HIV) (UNAIDS 2011). Table 2 and Figure 11 show the magnitude or prevalence and number of PLHIV in the five BRICS countries.

HIV/AIDS is a generalized epidemic in South Africa but a concentrated epidemic in Brazil, Russia, India, and China that is centred among highly stigmatized, difficult-to-reach populations, such as IDUs, sex workers, prisoners, and MSM. There is mounting evidence that, within all four countries, the epidemic is steadily spreading beyond core at-risk groups into the general population (Morrison and Kates 2006). 


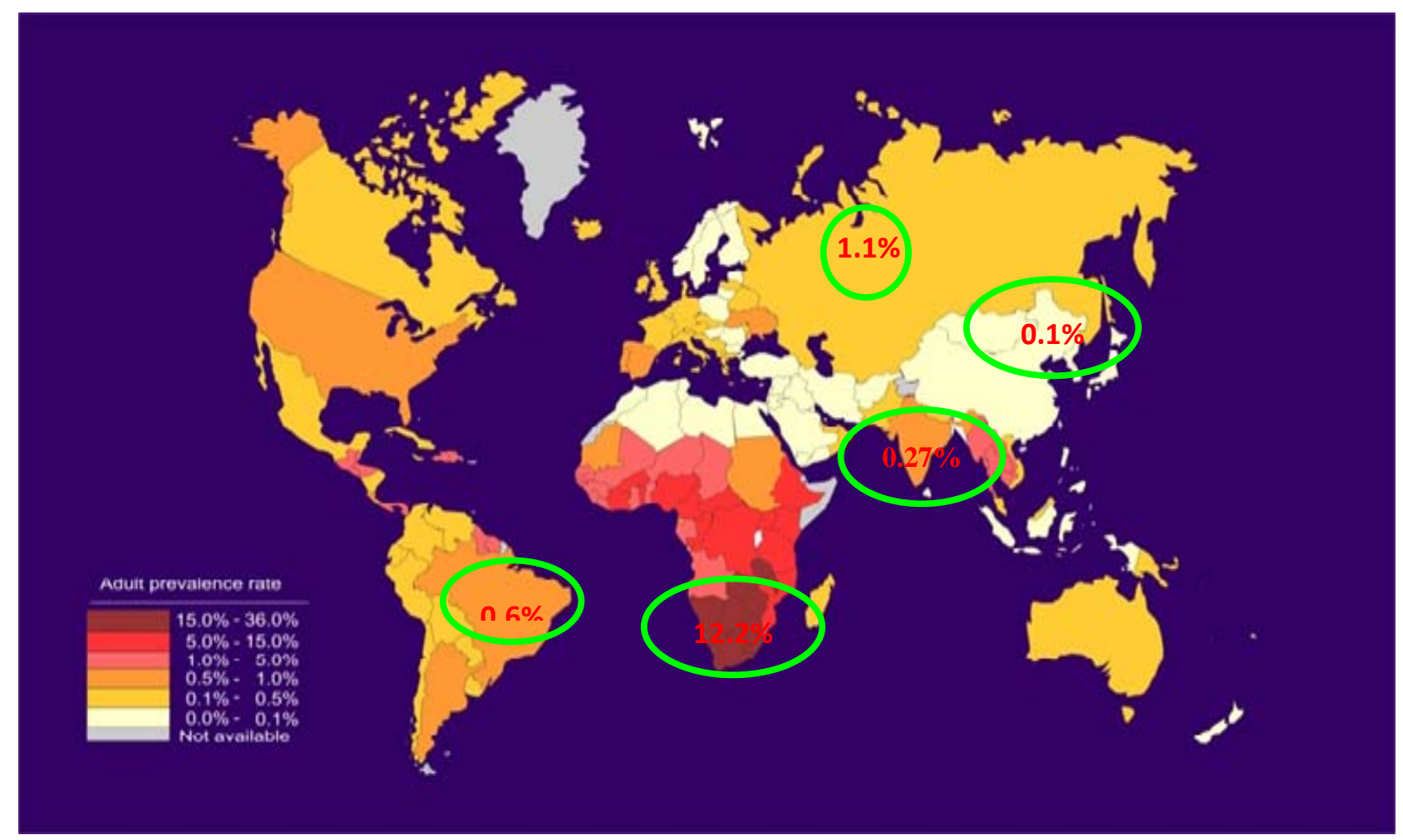

Figure 11. Magnitude of HIV/AIDS in BRICS Countries (2012).

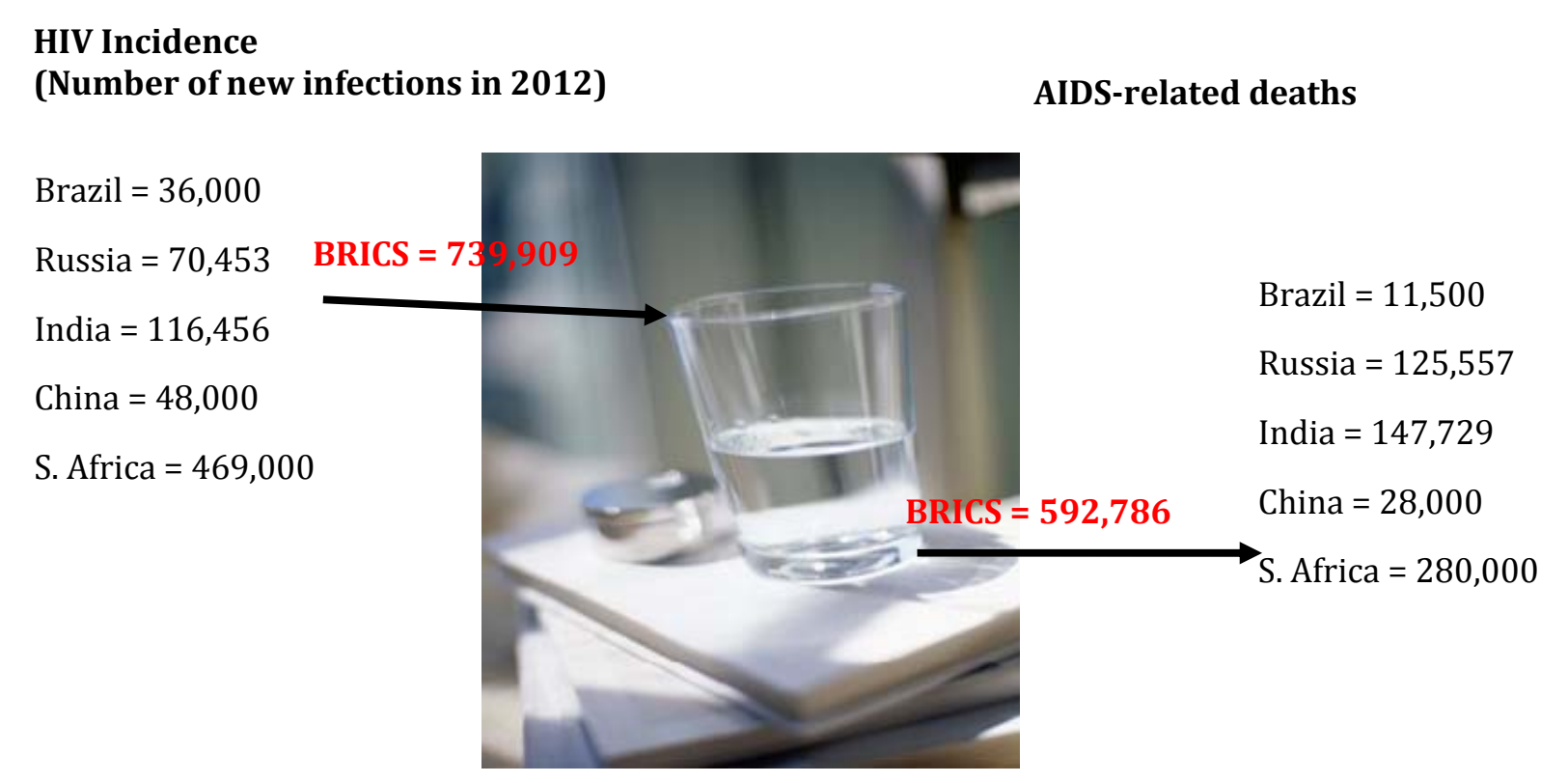

Figure 12. HIV Incidence \& AIDS-Related Deaths in BRICS (2012). Sources: Avert (2013a; 2013b). 


\section{DEADLY TREND}

While many countries with large numbers of people living with HIV have fewer new cases each year, Russia's epidemic is expanding.

\section{CHANGE IN NEW HIV} CASES, 2002 TO 2012

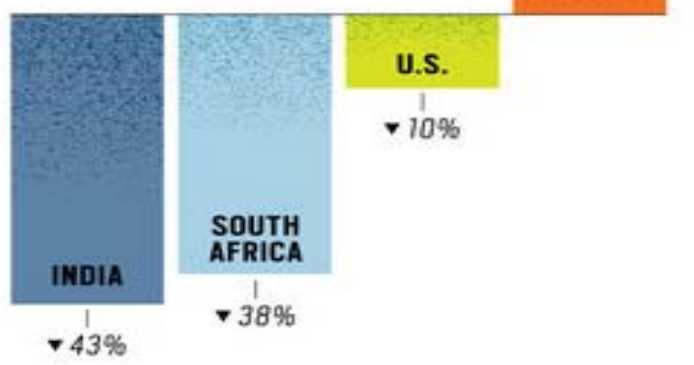

NUMBER OF PEOPLE LIVING WITH HIV, IN MILLIONS

\begin{tabular}{lll}
1 & SOUTH AFRICA & 6.1 \\
\hline 2 & NIGERIA & 3.4 \\
\hline 3 & INDIA & 2.1 \\
\hline 4 & KENYA & 1.6 \\
\hline- & MOZAMBIQUE & 1.6 \\
\hline 6 & TANZANIA & 1.5 \\
\hline- & UGANDA & 1.5 \\
\hline 8 & ZIMBABWE & 1.4 \\
\hline 9 & RUSSIA & 1.3 \\
\hline 10 & MALAWI & 1.1 \\
\hline- & U.S. & 1.1 \\
\hline- & ZAMBIA & 1.1
\end{tabular}

Sources: CDC, Russian Fedenal AIDS Center, UNAIDS

Figure 13. Change in New HIV Cases in Russia, India, and South Africa (2002-2012).

Table 1. HIV/AIDS Epidemic Patterns in BRICS

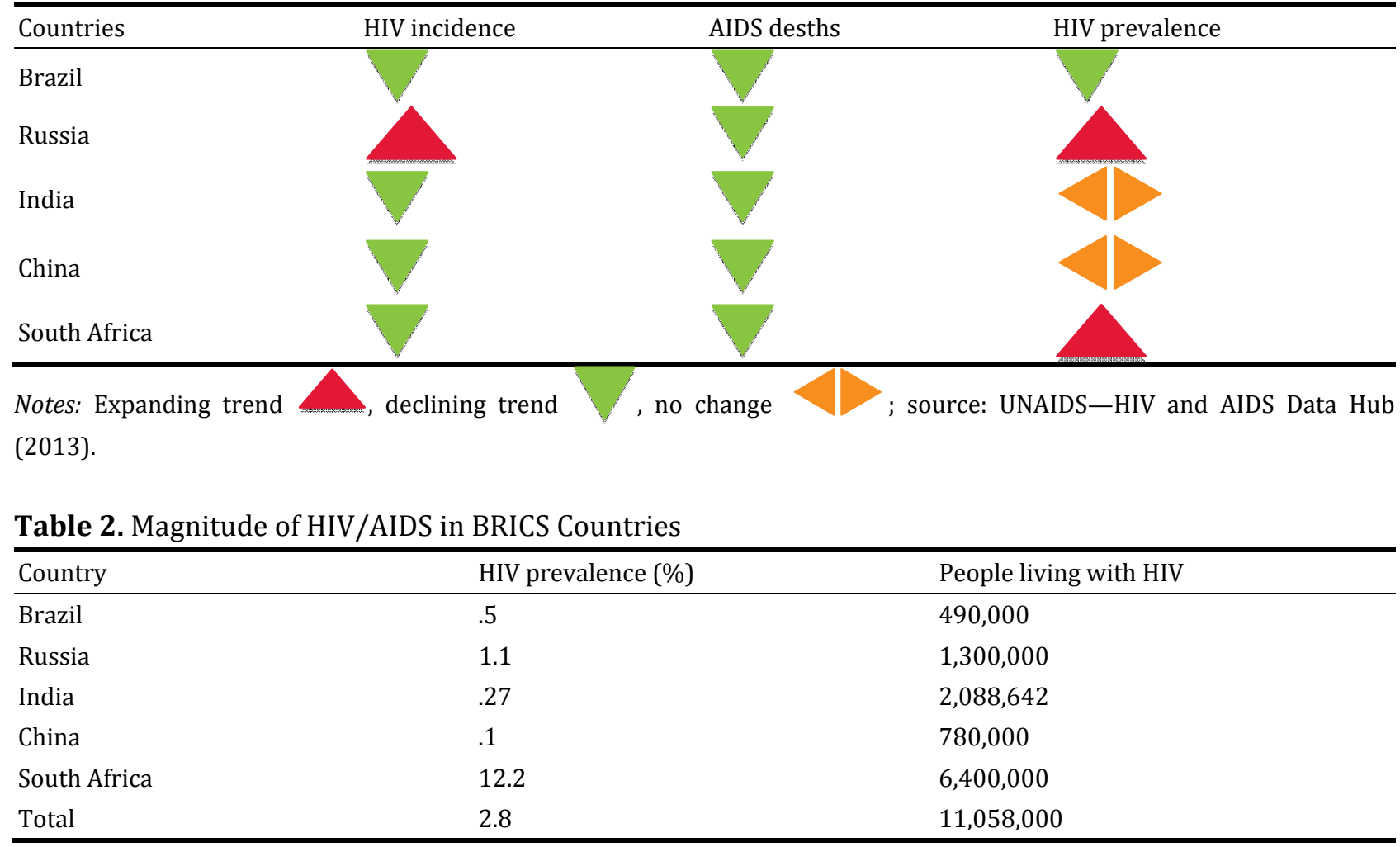

Note: Source: WHO (2013). 


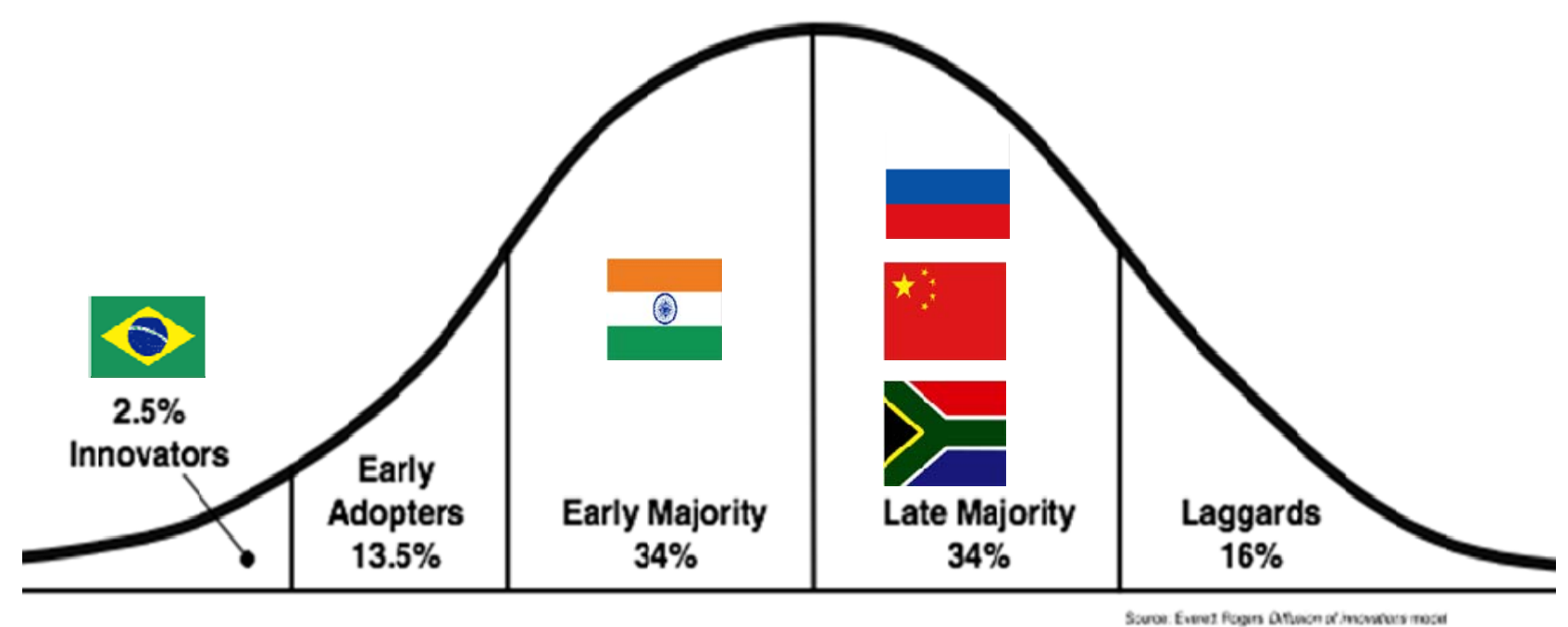

Figure 14. Analysis of Responses to HIV/AIDS in BRICS Using the Diffusion of Innovation Theory. Source: Boston University. Diffusion of Innovation Theory ${ }^{1}$.

\section{Modes of Transmission for HIV/AIDS in BRICS}

HIV/AIDS is mostly related to most-at-risk and vulnerable populations such as commercial sex workers (CSW), MSM, IDUs and bridge populations that include migrant workers, long distance truck drivers and prisoners. Examples of risk factors include unprotected sex with a partner whose HIV status is unknown, multiple sexual partnerships involving unprotected sex, and injecting drug use with contaminated needles and syringes (International HIV/AIDs Alliance 2011).

MSM continue to be at considerably higher risk of acquiring HIV infection worldwide than men overall. A variety of studies have found the HIV prevalence among men who have sex with men in capital cities to be an average 13 times higher than in the country's general population (UNAIDS 2013). In Brazil and South Africa, most of the people becoming infected with HIV at the start of the epidemic were MSM. However, since the early 1990s, more cases of AIDS have been attributed to heterosexual transmission than homosexual transmission in both countries (Avert 2013a; Avert 2012). South Africa is the only country in sub-Saharan Africa where gay rights are formally recognised. Moreover, national policies strongly emphasise equity, social justice and forbid discrimination based on sexual orientation. These are prerequisites for the provision of HIV services for MSM as well as other members of the lesbian, gay, bisexual and transgender (LGBT) community (Rispel et al. 2011). As a result, South Africa has the potential to provide a leading role in the improvement of HIV service provision for MSM in BRICS.

Figure 14 summarises the analysis of responses to HIV/AIDS in BRICS using the diffusion of innovation theory. The authors' assessment of responses to HIV/AIDS in BRICS is that Brazil was quick off-the-mark and qualifies to be innovators. India was shocked by the statistics in the early 2000s and became part of the early majority in their response. South Africa lost valuable time in the early 2000s, questioning whether HIV causes AIDS and querying the toxicity of ARVs. However, they seem to have turned the corner in their response. China's prevalence has remained low but the epidemic is becoming severe in some areas. Russia's epidemic is expanding and is currently one of the world's fastest-growing HIV epidemics. 


\section{LIMITATIONS OF THE STUDY}

There are some limitations associated with this study. Firstly, this study was limited to the context of five self-selected BRICS countries. The countries have heterogeneous epidemiological and socio-economic contexts. Thus, the study findings are only analytically generalizable. Secondly, the analysis focused on national level (macro-level) responses and may not reflect meso and micro-level situations in the case countries. Thirdly, the study is limited to the five broader thematic areas and information extraction is limited to these thematic areas only. Besides, limitations related to data availability and quality as well as the value-nature of the analysis methods should be taken in to consideration in the interpretation of the findings.

\section{CONCLUSIONS}

Although BRICS countries have collectively done well in dealing with HIV, it is concluded that they are far from winning the war against HIV/AIDS. The authors conclude with the good, the bad, and encouraging news from this analysis.

The good news is that Brazil responded early and firmly and has stabilized the epidemic at .6\% and has almost eliminated MTCT of HIV/AIDS. The epidemic is only concentrated to MSM, IDU, and SWs. UNAIDS named Brazil as a model country in the fight against HIV/AIDS in 2012. The promising news is that although India and South Africa have among the largest burdens of HIV/AIDS in the world both have turned the corner and have recorded huge declines in new HIV infections in recent years. The encouraging news is that China's prevalence has remained low (.058\%), even though the epidemic is becoming severe in some areas. The bad news is that the Russian Federation's epidemic is expanding and is currently one of the world's fastest-growing HIV epidemics.

There is a lot that BRICS countries need to do to reduce new infections. For example, Brazil can share lessons with other BRICS countries on how they kept the epidemic under check, Russia needs to put more effort to provide clean needles to reduce the fast growing HIV new infections, India and South Africa need to focus on young women and marginalised groups, and China needs to target minorities and high-transmission areas.

\section{Funding}

This work was funded by the Human Sciences Research Council.

\section{Note}

1. Retrieved (http://sphweb.bumc.bu.edu/otlt/MPH-Modules/ SB/SB721-Models/SB721-Models4.html).

\section{References}

Acharya, S., S.-L. Barber, D. Lopez-Acuna, N. Menabde, L. Migliorini, J. Molina, ... P. Zurn. 2014. "BRICS and Global Health.” Bulletin of the World Health Organisation 92(6):386.

Amirkhanian, Y. A., D. V. Tiunov, and J. A. Kelly. 2001. "Risk Factors for HIV and Other Sexually Transmitted Diseases Among Adolescents in St. Petersburg, Russia.” Family Planning Perspectives 33(3):106-112.

Avert. 2012. History of HIV/AIDS in South Africa. Retrieved (http://www.avert.org/history-hiv-aids-south- africa.htm).

- 2013a. History of HIV/AIDS in Brazil. Retrieved (http://www.avert.org/history-hiv-aids-brazil- htm).

- 2013b. HIV/AIDS in India. Retrieved (http://www. avert.org/india-hiv-aids-statistics.htm\#sthash.T2TccJMk.dp uf).

Decoteau, C. 2013. Ancestors and Antiretrovirals: The Biopolitics of HIV/AIDS in Post-Apartheid South Africa. Chicago: University of Chicago Press.

Department of STD, AIDS and Viral Hepatitis. 2012. AIDS in Brazil, 2012. Retrieved November 1, 2014 (http://www. aids.gov.br/en/pagina/aids-brazil).

Gomez, E. J. 2013. The BRICS Respond to Disease: International Politics and Historical Policy Backlash in Comparative Perspective. King's College London, King's International Development Institute. Retrieved (http://www. edgomez.org/images/BRICSHealthJune25-1.pdf). 
Government of India. 2012. HIV Estimations 2012 Report. Retrieved (http://pib.nic.in/newsite/printrelease.aspx?relid $=89785)$.

Haregu, T. N., B. Oldenburg, J. Elliott, and G. Setswe. 2013. "Global Responses to HIV/AIDS and Non-Communicable Diseases: Analysis of Similarities and Differences.” $\mathrm{Br} \mathrm{J}$ Med Med Res 3(2):442-465.

International HIV/AIDs Alliance. 2011. Who Are Vulnerable and Most-at-Risk Populations. Retrieved (http://www.aidsalliance.org/includes/Document/Preventio n\%20ca mpaign/Campaign-Policy-Briefing-1.pdf).

Kozlov, V. 2011. "Social Diseases (HIV and TB) and Population Health in Russia.” Presented at BSPS Annual Conference, York, UK.

Kulik, J. 2013. Reducing the Economic Burden of Non-Communicable Diseases in the BRICS: Lessons From Brazil. BRICS Research Group University of Toronto, January 25, 2013. Retrieved (http://www.brics.utoronto.ca/ biblio/Kulik-NCDs-Brazil.html).

Lieberman, E. 2009. Boundaries of Contagion: How Ethnic Politics Have Shaped Government Responses to AIDS. Princeton: Princeton University Press.

Ministry of Health of the People's Republic of China. 2012. China AIDS Response Progress Report. Retrieved (http://www.avert.org/hiv-aids-china.htm\#footnote1_4yniof c).

Morrison, J. S. and J. Kates. 2006. The G-8, Russia's Presidency, and HIV/AIDS in Eurasia: A Report to the CSIS Task Force on HIV/AIDS in Collaboration With the Kaiser Family Foundation 4 (2006). Center for Strategic \& International Studies (CSIS) \& Kaiser Family Foundation. Retrieved (http://csis.org/files/media/csis/pubs/060614_ g8aids.pdf).

National AIDS Coordinating Organisation (NACO). 2012. Technical Report India HIV Estimations, 2010. Government of India: NACO and National Institute of Medical Statistics.

Onishchenko, G. 2013. Official Letter to Heads of Regional Departments of the Federal Consumer Rights and Healthcare Supervisory Service, 2013. Moscow: Federal Consumer Rights and Healthcare Supervisory Service.

Parker, R. 2009. "Civil Society, Political Mobilization, and the Impact of HIV Scale-Up on Health Systems in Brazil.” $J$ Acquir Immune Defic Syndr 52:S49-S51.

Rispel, L. C., C. A. Metcalf, A. Cloete, J. Moorman, and V. Reddy. 2011. "You Become Afraid to Tell Them That You Are Gay: Health Service Utilization by Men Who Have Sex With Men in South African Cities.” Journal of Public Health Policy 32(1):137-151. Retrieved (http://www.avert. org/hiv-aids-south-africa.htm\#footnote11_yr0rode).

Russia Beyond the Headlines. 2012. HIV Rate Is 12\% Up in
Russia in 2012. Retrieved (http://rbth.com/articles/2012/ 11/28/hiv_rate_is_12_up_in_russia_in_2012_20491.html).

Sandelowski, M., C. I. Voils, J. Leeman, and J. L. Crandell. 2012. "Mapping the Mixed Methods-Mixed Research Synthesis Terrain.” J Mix Methods Res 6:317-331.

Shisana, O., T. Rehle, L. C. Simbayi, K. Zuma, S. Jooste, D. Onoya, ... N. Zungu. 2014. South African National HIV Prevalence, Incidence and Behaviour Survey, 2012. Cape Town: HSRC Press.

South African National AIDS Council (SANAC). 2012. National Strategic Plan for HIV, STIs and TB 2012-2016. Retrieved (http://laylacassim.co.za/pdf/National\%20 Strategic\%20Plan\%20on\%20HIV,\%20STIs\%20and\%20TB .pdf).

Statistics South Africa. 2013. Mortality and Causes of Death in South Africa, 2010: Findings From Death Notification. Pretoria: Statistics South Africa.

UNAIDS (The Joint United Nations Programme on HIV and AIDS). 2011. HIV/AIDS Estimates. Retrieved (http://www.unaids.org/en/regionscountries/countries/).

_ . 2013a. "Three Ones” Key Principles, 2012. Retrieved (http://data.unaids.org/una-docs/three-ones_keyprinciples_e n.pdf).

- 2013b. Global Report: UNAIDS Report on the Global AIDS Epidemic 2013. Geneva: UNAIDS.

- 2014a. Global Report: UNAIDS Report on the Global AIDS Epidemic, 2013. Geneva: UNAIDS.

—. 2014b. The Gap Report. Geneva: UNAIDS. Retrieved (http://rbth.com/articles/2012/11/28/hiv_rate_is_12_up_in_ russia_in_2012_20491.html).

UNGASS (United Nations General Assembly Special Session). 2010. China 2010 UNGASS Country Progress Report (2008-2009). Retrieved (http://data.unaids.org/pub/ Report/2010/china_2010_country_progress_report_en.pdf).

— 2013. China AIDS Response Progress Report. Ministry of Health of the People's Republic of China, 2012. Retrieved (http://www.avert.org/hiv-aids-china.htm\#foot note1_4yniofc).

UNODC (United Nations Office on Drugs and Crime). 2012. World Drug Report, 2012. Geneva: United Nations.

Wallander, C. 2005. "The Politics of Russian AIDS Policy." PONARS 389. Retrieved (http://www.gwu.edu/ ieresgwu/ assets/docs/ponars/pm_0389.pdf).

WHO (World Health Organization). 2011. The WHO Health Systems Framework. Retrieved (http://www.wpro.who. int/health_services/health_systems_framework/en/).

- 2013. Global Health Observatory (GHO). Retrieved (http://www.who.int/gho/ hiv/en/).

- 2014. Global Health Observatory (GHO): HIV/AIDS. Retrieved (http://www. who.int/gho/hiv/en/).

Wu, Z., S. Sullivan, Y. Wang, J. Rotheram-Borus, and R. 
Detels. 2007. "Evolution of China's Response to HIV/AIDS.” Lancet 369:679-690.

\section{Bios}

Geoffrey Setswe, DrPH, RN., BRICS Research Centre, Human Sciences Research Council, South Africa; research fields: behavioural and social aspects of HIV/AIDS.
Olive Shisana, ScD, chief executive officer, Evidence Based Solutions, South Africa; research fields: social epidemiology of HIV/AIDS and public health issues.

Nompumelelo Zungu, Ph.D., BRICS Research Centre, Human Sciences Research Council, South Africa; research fields: psycho-social aspects of HIV/AIDS and health issues.

Matshaba Mothiane, MA, BRICS Research Centre, Human Sciences Research Council, South Africa; research fields: political and economic aspects of HIV/AIDS. 